\title{
Mobile Health Technology (Mhealth) in Combating COVID-19 Pandemic: Use, Challenges and Recommendations
}

\author{
Shekinah Yobuh Williams 1,2,3 (D), Shalom Oluwafunke Adeyemi ${ }^{2,4}$ (D), James Oluwadara Eyitayo ${ }^{1}$ (D), \\ Olubunmi Emmanuel Odeyemi ${ }^{1,3^{*}}$ (D), Olaoluwa Ezekiel Dada ${ }^{1}$ (D), Miracle Ayomikun Adesina ${ }^{5}$ (D), \\ Abiodun David Akintayo ${ }^{1,2,3}$ \\ ${ }^{1}$ Department of Medicine and Surgery, College of Medicine, University of Ibadan, Oyo State, Nigeria \\ ${ }^{2}$ Student Research Network, University of Ibadan, Nigeria \\ ${ }^{3}$ College Research and Innovation Hub $(\mathrm{CRIH})$, Nigeria \\ ${ }^{4}$ Faculty of Pharmacy, University of Ibadan, Ibadan, Oyo State, Nigeria \\ ${ }^{5}$ Slum and Rural Health Initiative, Ibadan, Oyo State, Nigeria \\ * Corresponding author: Olubunmi Emmanuel Odeyemi E-mail: emmabunmite@gmail.com ORCID: 0000-0003-1386-8936 \\ Received: 28 May 2020 Accepted: 13 July 2020
}

\begin{abstract}
The novel coronavirus disease was discovered first in Wuhan, China in December, 2019. It was later declared a pandemic by the World Health Organization (WHO) on the 11 th of March, 2020. COVID-19, as popularly called, has spread rapidly to about 213 countries of the world and 2 international conveyances. There are over 5.8 million confirmed cases of coronavirus infection as at May 28th, 2020 and more than 358 thousand death cases reported globally. This staggering statistics has called for drastic and concerted efforts from governments and health workers around the globe to combat COVID-19 pandemic. With the increasing need for effective prevention of spread of the virus and development of a cure and a vaccine for COVID-19 as soon as possible, mobile health technology with all its benefits may just be the answer.

Mobile Health technology has been a vital tool in creation of awareness and dissemination of information; as a means of curtailing the spread of the coronavirus from person to person; tracking of infected persons, and reduction of person-toperson contact, virtual screening and remote monitoring of patients. Despite the aforementioned uses, the challenge of cost, information privacy and less knowledge of the application of mhealth remains. It is therefore recommended that the potential of low-cost mobile technology be maximized; laws and regulation as regard privacy and confidentiality be set and funds be made available by the government.
\end{abstract}

Keywords: mHealth, mobile health technology, digital technology, COVID-19 


\section{INTRODUCTION}

Since mobile phones came into the market about four decades ago, it has had significant success and undergone rapid advancements [1]. More people are making use of mobile phones in that about 62.9 percent of the global population owns a mobile phone as at 2016 [2]. In the developing world, nearly 70 percent of the population own a mobile phone and the number is increasing steadily [3]. Mobile technology is developing at a rapid rate, increasing connection and communication amongst people. Consumer's demand for more wireless gadgets and applications is leading to a paradigm shift in the health care industry towards increasing dependence on mobile technology. Health professionals look forward to more convenient and faster ways of accessing patients' records without being confined to their offices. Patients find it easier to consult with their doctors and receive vital health information and patient's record has been made more accessible to health workers. Mobile technology enhances collaboration among health care workers worldwide and therefore the process of making decision is faster. With this significant impact, we are only beginning to witness the rise and domination of mobile health technology in health care delivery $[1,4]$.

Currently there is no universally embraced definition for mHealth [5]. However, it has been defined differently by many professionals and organizations. The World Health Organization defines mobile health (mHealth) as the provision of health services and information via mobile and wireless technologies [5]. Dr. Watson of University of Pittsburgh Medical Centre (UPMC) defines mHealth as simply the evolution of healthcare into the virtual world using highly portable devices [6]. The National Institute of Health defines mHealth as the use of mobile and wireless devices to improve health outcomes, health care services, and health research [6].

Mobile Health (mHealth) is an important aspect of electronic health (eHealth). The World Health Organization (WHO) defines eHealth as the cost effective and secure use of information and communications technologies (ICT) for health and health-related fields, including health care services, health surveillance, health literature, health education, knowledge and research [7]. Recently, digital health was introduced as a term encompassing eHealth as well as emerging areas, such as the use of advanced computing sciences in big data, genomics and artificial intelligence [8]. Mobile health technology is proving to be of great importance in the delivery of health care services and the promotion of public health. Different kinds of devices such as mobile phones, personal data assistant (used as personal information manager), patient monitoring devices, wearable devices and some wireless gadgets that contain health information support mobile health [9]. The relevance of mobile wireless technologies are evident in their broad reach, user-friendliness and wide acceptance. Studies from the International Telecommunications Union (ITU) in Geneva shows that as at 2015, there were more than 7 billion mobile phone subscriptions across the world with low- or middle-income countries making over $70 \%$. People in lowor middle-income countries were less likely to have access to clean water, electricity or a bank account than to a mobile phone. Access to health information and services through the use of mobile phones and mobile-based services such as smart phone applications and SMS is on the increase [10-12]. With the growing ownership of mobile phones worldwide, the utilization of mobile health technology is a probable way of providing high-impact and low-cost solutions to effectively combat a disease of public health concern like COVID-19 [13].

There is the COVID-19 pandemic caused by the novel coronavirus. It was firstly reported on the 29th of December 2019 in Wuhan, Hubei province of China and officially named the coronavirus infectious disease 2019 (COVID-19) by the World Health Organization (WHO) [14-16]. This novel coronavirus is also known as Severe Acute Respiratory Syndrome Coronavirus 2 (SARS-CoV-2) [17].

The coronavirus is a family of enveloped single-stranded RNA viruses which are known to affect the respiratory system and produce symptoms similar to the common cold such as fever, sore throat, sneezing, runny nose and or more severe respiratory symptoms such as difficulty in breathing, pneumonia and lung infection. Hepatic, enteric and neurologic symptoms have also been identified [18-20]. Coronaviruses are known to be zoonotic viruses but few cases have been identified in humans. According to guidelines from the Chinese health authorities, COVID-19 is spread through droplet, contact and aerosol transmissions [21]. Early patterns of spread of this virus have simulated that of the Severe Acute Respiratory Syndrome coronavirus and the Middle East Respiratory Syndrome coronavirus [22].

According to the WHO situation report on May 27, 2020, there are 5,488,825 cases and 349,095 deaths worldwide with cases reported in Africa, Americas, Eastern Mediterranean, Europe, South-East Asia and Western Pacific [23]. 
Coronavirus, COVID-19 has spread to over 213 countries and territories across the globe and 2 international conveyances [24]. The few countries that have not reported coronavirus includes: Kiribati, Micronesia, North Korea, Solomon Island, Nauru, Palau, Samoa, Turkmenistan, Tonga, Marshall Islands, Tuvalu and Vanuatu [25].

With no vaccine for COVID-19 approved yet, avoiding exposure to the virus remains the best preventive method [21].

The rapid transmission of this novel coronavirus calls for very swift, effective and coordinated response from the governments of all countries and health care workers world wide in combating this pandemic [26].

\section{APPLICATION OF MHEALTH IN FIGHTING COVID-19}

\section{Creation of Awareness}

Provision of useful information and warning people in realtime is important in combating a pandemic like COVID-19. Mobile health technology provides different categories of audiences with around-the-clock access to high quality information at low cost via text messages and mobile applications. Public Health-Seattle and King County carried out a research in which $82 \%$ of respondents showed willingness to receive text messages during an actual emergency situation [27]. A 2010 study in Epidemiologic Reviews [27] reported that text message is useful for passing information, educating the public and encouraging behavioral change. Reminder-text messages can be used to promote adherence to preventive measures such as curfew, nose-mask wearing, hand washing with alcohol-based hand sanitizers, etc. [27]. Another effective way of creating health awareness through mobile technology is the use of infographics. In Nigeria, the Slum and Rural Health Initiative, SRHIN, developed infographics that encourage proper hand hygiene, social distancing and consultation with a medical doctor, as part of ongoing efforts to combat COVID-19. These were translated into over 60 African languages and circulated via social media platforms. This way, vital health information was successfully passed to several groups of people.

Short video contents uploaded through Youtube and mobile games are creative and useful ways of disseminating information about COVID-19 through mobile technology [28].

Reference and training materials for health-care professionals can be downloaded onto their phones and used in the management of COVID-19 patients [13].
Regular websites visited by people is very effective in passing warning information to the public [29,9]. In emergency situations effective transmission of information helps to provide reassurance and reduce panic among people [30].

\section{Health Survey and Health Surveillance}

Health survey and surveillance entails making use of mobile devices for data collection, data inputting and transmission in health-related activities for the purpose tracking of diseases [5]. After the 2012 earthquake in Haiti, the mobile phone was successfully used to map the spread of cholera by tracking of human population movements through the use of geolocation coordinates [13].

Mobile technology was also used during the Ebola scare to track movement of people and identify locations to focus preventive measures [29].

The use of cell phone and satellite technology in health surveillance can be used to monitor the movement of people potentially infected with the coronavirus and trace their contacts. Several companies are developing mobile technologies for health surveillance in the COVID-19 fight.

In China [31], the Alipay Health Code system was developed by Alibaba and Ant financial. It uses a mobile application; the Alipay app; to generate a rating of a person's coronavirus infection risk. Based on assessment of symptoms and travel history the app assigns an individual either green, yellow or red color codes. People [32] with code green are allowed to move about without restrictions while a person with yellow code is asked to self isolate for seven days. Any individual with code red is quarantined for fourteen days. This code system enables the government and business organizations to limit contact between potentially infected and uninfected persons.

In Israel [33], the ministry of health launched a smartphone application to aid the prevention of coronavirus spread. The app, known as Hamagen (The Shield) determines if the user has come in contact with a coronavirus infected person in the preceeding 14 days. The app tracks and compares movements and locations of the user with that of patients previously diagnosed of coronavirus infection. Any match detected is reported to the Ministry of health and appropriate measures are taken [26].

Websites such as the coronamap.site; used in South Korea; is used to warn residents of identified locations about the presence of coronavirus infected persons such area [34]. 


\section{Reduction of Person-to-Person Contact}

Given the fact that one of the major ways by which coronavirus is spread is through contact with infected persons, an important preventive strategy in fighting COVID-19 would be to reduce person-to-person contact to the minimum [21]. The World Health Organization flagged activities such as cash payments; having the risk of increasing person-to-person contact; as a conduit for spreading the coronavirus.

In a bid to reduce person-to-person contact, governments and organizations have turned to mobile health technology for solution [35]. In some African countries a large volume of transactions have been shifted towards digital payments instead of the popular cash payments [35]. In Kenya, mobile money is being utilized as a public-health tool, to reduce contact between customers and employees. Safaricom [36], the largest telecom in the country; and owners of mobile money platform, M-Pesa; waived fees for all transfers under 1,000 shillings in a bid to discourage cash payments, which require person-to-person contact. In South Africa, Yoco, a small-business payments startup, developed a remote payment service to enable transfers on its customer network through a weblink, thereby decreasing unnecessary personto-person contact [35]. During the lockdown period in Uganda [36], market women helped to prevent the spread of coronavirus by making use of a mobile app, the Market Garden, to sell agricultural produce from home instead of selling from the market. Motorcycle and taxis were used deliver the products to the customers while payment was made through the platform.

This service prevented unnecessary contact and exchange of currency between persons, an important preventive measure against COVID-19 [36].

\section{Virtual Screening and Monitoring}

Mobile based health information systems are increasing the capacity for managing, monitoring and treating patient's illness from a distance - Telemedicine [5]. Mobile technology provides more accurate and quality data, reduces time taken for data collection and the cost of monitoring health outcomes [5]. With this mobile technology service, people with symptoms suspicious of COVID-19 can connect with a doctor remotely, report their symptoms and undergo prescreening through a mobile application.

In virtual monitoring, remote sensors that measure patients' biosignals and communicate wirelessly with a mobile device are worn on the body. The mobile device is used to transmit alarms and biosignals of patients to a secure online database of a health care centre which can be accessed by a remote health care provider through a mobile application [5].

Over 1 million people in Singapore [30] have made use of a telehealth application called MaNaDr, for virtual consultation with a doctor. Through this platform, physicians advise patients based on the severity of symptoms reported to stay at home, take specific medications or actually visit the hospital. Remote monitoring of progression of symptoms in real-time continues while the need for emergency transport to a hospital for intensive care management is assessed and an ambulance provided for patients with worsening symptoms. This prevents over-flooding of hospitals and over working of doctors while ensuring easier provision of health care across distance.

In the United States patients can measure their health parameters and have doctors access them from a cloud where they are stored automatically after they are uploaded [30].

\section{Decision Support Systems for Health Care Providers}

Decision support systems make use of software algorithms and checklists. These assist health care providers in making clinical diagnoses according to protocols and guidelines by comparing patient health data with medical information. A mobile device is used to input data as well as receive the targeted health information. This is a very useful feature for helping clinicians in remote areas make diagnosis and triage patients [9].

Patients themselves can benefit directly from this technology. People with symptoms suspicious of COVID-19 could enter their symptoms into a mobile-based application which provides a checklist or protocol that guides decision making - to self isolate or see a doctor. This reduces unnecessary consultation of doctors. The limitation here is that coronavirus is not fully understood so this system may not be accurate in making decisions in the management of COVID-19 infected patients.

\section{Communication and Collaboration Among Health Care Providers}

Mobile health technology systems makes communication among health professionals possible through telemedicine [4]. Telemedicine entails consultation and or communication among health care providers about patients via text, voice, video or imaging using a mobile phone [5]. 
Mobile Doctors Network (MDNet) is a mobile technology service used in Ghana that provides doctors with twenty four hours access to free mobile telephone service.

This mHealth application makes it easy for health care providers in different facilities and in different parts of the world to share health information, receive updates with their mobile phones securely and in real-time, thus, increasing the speed of providing care. It also facilitates emergency response communication among physicians [5].

In combating COVID-19, using this kind of system will enhance collaboration [6] among healthcare providers in different health care centers and in different countries. This is very important in effectively implementing coronavirus infection prevention measures worldwide.

mHero is another mobile phone-based two-way communication system that uses text messaging service to enhance communication between ministries of health and health workers during an emergency [37].

The use of such a system in managing COVID-19 ensures uniformity in the information passed to health workers. It also bypasses the bureacracy and unnecessary protocols that slow the transmission of information down the chain of command.

\section{Data Collection and Patient Records}

Collection of data is central to developing preventive strategies and measures to stop the spread COVID-19. Mobile technology increases the speed of data collection via remote-data collection systems and communication services supported by mobile phones and personal data devices [5]. This makes data more readily available and easier to transfer.

OpenMRS-Ebola is an electronic health record system that was successfully built and used during the Ebola outbreak in Sierra lone. The system operated on a tablet-based mobile application for wards with infectious patients and desktopbased application for the noninfectious. The system enabled registration of 112 patients. The significant benefit of the OpenMRS-Ebola was the effective collection of data in highly infectious environments during an emergency [38].

Such system can be successfully used by health care workers in the collection of data from patients infected with COVID19 in the hospital while still maintaining prevention and control measures. This technology will enable health professionals to work effectively and also minimize their contact with COVID-19 infected patients.
Moreso, Open Medical Record System (open MRS) enables more effective management of patient referrals - specialists can rapidly share patient information, make decisions and refer patients on time [37] from hospitals with less facilities to hospitals with better facilities such as COVID-19 testing kit, ventilators and intensive care units, etc.

\section{Coordination of Emergency Response and Transport}

In the context of mHealth public health emergency response entails making use of mobile devices for responding to and managing emergency and disaster situations. Forms of mHealth application during emergencies includes alert systems, citizen communication, transportation dispatch and reporting through short message services and voice telephony on mobile phones [5].

As part of coordination of emergency response during the 2010 earthquake in Haiti, SamaSource, Ushahidi and FrontlineSMS collaborated to create a mapping system of citizen reporting via mobile phones. This allowed citizens to communicate their needs and or report a missing individual by sending SMS text to a standardized shortcode. SMS texts were translated to English, uploaded and plotted on a Haiti map via the Ushahidi platform [5]. This system helped in meeting citizens needs as well as tracking missing persons.

Such a system can be utilized in combating COVID-19 especially in areas with very high numbers of coronavirus infected persons. Using this kind of technology, people living in these places will be able to report cases of coronavirus infected persons that need emergency service. With the aid of this mapping system the emergency response team effectively determine which places to channel resources more.

\section{CHALLENGES ASSOCIATED WITH THE USE OF MOBILE HEALTH TECHNOLOGY}

In spite of the improvements mobile health technology has brought to health care delivery there still exists some significant challenges with its use that cannot be overlooked.

\section{Poor Access to Technology among Vulnerable Groups}

A lot of people who dwell in very rural areas, slums, IDP (Internally Displaced Persons) camps, etc. do not have access to smart phones or do not have access to a phone at all [39].

Creating awareness of COVID-19 through mobile technology services such as SMS text messaging, use of mobile phone applications etc among people who do not have access to a phone becomes impossible. As a result of 
lack awareness of the coronavirus this category of people will not be able to adhere to common preventive measures such as maintaining social distancing, self isolation and washing of hands with sanitizers etc.

\section{Maintenance of Privacy and Confidentiality}

Already, legitimate concerns over the safety of patients' health records exists with the use of paper records [40]. As a result of the way digital technology makes it easier to analyze, manipulate and reproduce electronic health records, several cases of data breaches by government enterprises and commercial organizations have been reported. Many people have had their health information obtained illegally and used for mischievous purposes [40].

With advancements in technology the possibility of tracking of location via mobile phone networks, installments of surveillance camera on streets, monitoring of digital cash transfers and internet transactions make maintenance of privacy difficult [40].

\section{Lack of Knowledge about Possible Applications of mHealth}

A 2009 study carried out by WHO among member states showed that lack of knowledge concerning the various possible applications of mobile health technology was the second highest rated barrier to implementation of mHealth [3].

Even though mobile technology will significantly strengthen our fight against COVID-19, lack of knowledge about how it can be effectively used to combat this pandemic will only hinder its application in combating this pandemic [3].

\section{RECOMMENDATIONS}

\section{Focus on Low-cost Mobile Technology in Combating COVID-19}

While some forms of mobile health technology such as decision support systems may be more expensive to start up and operate focus should be shifted towards maximizing the potentials of low-cost mobile technology such as SMS messages, mobile phone applications, infographics, short videos, mobile games and website broadcasts to educate the public about coronavirus and encourage adherence to preventive measures as the fight against COVID-19 goes on. The advantage of focusing on low-cost technology is that its use is feasible in high, middle and low income countries.

\section{Increased Funding for Innovation and Research in COVID-19}

Scientists, researchers, and health care professionals all over the world are working towards finding a solution to COVID19. However, without sufficient funds not much can be done. In most cases outside groups fund most of technological innovation.

Governments should provide additional funds for the ministries of health and science and technology to drive research that is specifically targeted towards combating COVID-19.

Private establishments as well as the government should award grants for individuals, organizations to implement their innovative ideas, organize innovation competitions with sponsorship for winners in order to encourage maximization of the potentials of mobile technology in the fight against COVID-19.

\section{Protection of People's Privacy}

The use of mobile technology for tracking movement of people potentially infected with COVID-19 inevitably may require access to people's private information. The government, however, should take responsibility of ownership of patient data and play active role in setting regulations that ensure protection of people's information. Increased protection of private information will encourage the use of mobile technology in the fight against this coronavirus pandemic.

\section{CONCLUSION}

The novel coronavirus (Severe Acute Respiratory Syndrome Coronavirus 2, SARS-CoV-2) is an RNA virus spread through droplet, contact and aerosol transmissions that is currently causing the COVID-19 pandemic. It affects the respiratory system and produces symptoms similar to the common cold such as fever, sore throat, sneezing, runny nose and or more severe respiratory symptoms such as difficulty in breathing, pneumonia and lung infection. Currently, about 213 countries are affected, over 5.8 million cases and more than 358,000 deaths have been reported. The rapid spread of the virus has made the COVID-19 a public health emergency of international concern and governments together with health care professionals all over the world are relentlessly working to prevent its spread, develop a cure and vaccine for the virus. The importance of mobile technology in the health care industry holds a lot of promise in the fight against COVID-19. 
Mobile technology is growing at an exponential rate as mobile phone usage continues to increase world wide. There is an increasing dependence on mobile technology in health care delivery due to its significant contributions which include increasing the speed of decision-making, remote monitoring, enhancing communication among health care workers, easier collection and storage of data, increasing physician and patients' access to data, thus, providing better quality of care. During emergency situations like the COVID-19 pandemic mobile technology also improves health surveillance, education of the public and behavioral change communication.

In spite of all the benefits of mobile heath technology there exists some challenges such as breach of privacy, concerns over ownership of patient data, high cost of technology maintenance and lack of knowledge about mobile health technology, among others, that hinder the effective implementation of mHealth. These challenges however, can be overcome by increasing the utilization of low-cost mobile technology such as SMS text, mobile applications, mobile games, short videos; control of data ownership and regulation of use of patient's data by the government through policies and laws.

If all the potentials of mobile technology are maximized and the challenges overcome mobile health technology will prove to be a very powerful weapon that will be effective in combating the new public health emergency of international concern, the COVID-19. Therefore governments, health care workers, scientists and the private sector should work towards utilizing mobile health technology and harnessing its vast potentials as we combat COVID-19.

\section{ACKNOWLEDGEMENT}

The authors of this paper appreciate all the referred authors for their incredible work which served as a resource material in completing this review article.

\section{DECLARATION OF CONFLICT OF INTEREST}

The authors received no financial support for the research and/or authorship of this article. There is no conflict of interest.

\section{REFERENCES}

1. Varshney U. A model for improving quality of decisions in mobile health. Decision Support Systems 2014; 62: 66 77. (doi: 10.1016/j.dss.2014.03.005).
2. Statista: Mobile phone users worldwide 2015-2020. 2016. Available at: https://www.statista.com/statistics/274774/ forecast-of-mobile-phone-users-worldwide/ (Accessed: April 30, 2020).

3. World Bank Group. 2016. World Development Report 2016: Digital Dividends. Washington, DC: World Bank. Pp. 6. Available at: https://openknowledge.worldbank.org/ handle/10986/23347 (Accessed: May 20, 2020).

4. Sadiku M, Shadare A, Musa S. Mobile Health. Int J Eng Res 2017;6(11):450-2.(doi:10.5958/2319-6890.2017.00061.7).

5. WHO. 2011. mHealth: New horizons for health through mobile technologies: second global survey on ehealth. Global Observatory for eHealth series vol.3 Pp 6 . Available at https://www.who.int/goe/qublications/ ehealth_series_vol3/en/ (Accessed: May 20, 2020).

6. Health IT Outcomes: The rise of mHealth. 2013. Available at: https://www.healthitoutcomes.com/doc/the-rise-ofmhealth-0001 (Accessed: May 20, 2020).

7. WHO Emro: Ehealth. Available at: https://www.emro. whoint/healtheopics/ehealth/ (Accessed: May 20, 2020).

8. WHO guideline: recommendations on digital interventions for health system strengthening. Geneva: World Health Organization; 2019. Available at: https://www.healthynewbornnetwork.org/resource/wh o-guideline-recommendations-on-digitakinterventionsfor-health-system-strengthening/ (Accessed: May 20, 2020).

9. Davey S, Davey A. Mobile-Health: Can it strengthen and improve public health systems of other developing countries as per Indian strategies? A systematic review of the literature. Int J Med Public Health 2014; 4: 40-5. (doi: 10.4103/2230-8598.127121).

10. International Telecommunication Union. Measuring the information society report. 2015. Available at: https://www.itu.int/en/ITU-

D/Statistics/Documents/publications/misr2015/MISR20 15-w5.pdf (Accessed: May 2, 2020)

11. International Telecommunications Union: Mobile Cellular phone subscriptions, Key ICT indicators for developed and developing countries and the world (totals and penetration rates). Available at https://www.itu.int/en/ITU-D/Statistics/Pages/ publications/mis2015.aspx (Accessed: May 2, 2020). 
12. WHO: World Health Assembly, 71. (2018). Seventy-first World Health Assembly: Geneva, 21-26 May 2018: summary records of committees, reports of committees. World Health Organization. Available at https://apps.who.int/iris/handle/10665/325993 (Accessed: May 20, 2020).

13. O'Donovan J, Bersin A. Controlling Ebola through mHealth strategies. Lancet Glob Health 2015; 3(1): e22. (doi: 10.1016/S2214-109X(14)70357-2).

14. Li Q, Guan X, Wu P, Wang X, Zhou L, Tong Y, et al. Early transmission dynamics in Wuhan, China, of novel coronavirus-infected pneumonia. N Engl J Med 2020; 382: 1199-207. (doi: 10.1056/NEJMoa2001316).

15. CDC: Coronavirus Disease (COVID-19). 2020. Available at: https://www.cdc.gov/media/dpk/diseases-andconditions/coronavirus/coronavirus-2020.html (Accessed: May 20, 2020).

16. WHO: Novel Coronavirus - China [Internet].. Available at: https://www.who.int/csr/don/12-january-2020-novelcoronavirus-china/en/ (Accessed: May 20, 2020).

17. Medsacpe: Coronavirus Disease 2019 (COVID-19): Practice Essentials, Background, Route of Transmission. 2020. Available at: https://emedicine.medscape.com/ article/2500114-overview (Accessed: May 20, 2020).

18. WMHC. 2020. Wuhan Municipal Health and Health Commission's Briefing on the Current Pneumonia Epidemic Situation in Our City 2020. Available at: http://wjw.wuhan.gov.cn/front/web/showDetail/20191 23108989 (Accessed: May 20, 2020).

19. Zhu N, Zhang D, Wang W, Li X, Yang B, Song J. A novel coronavirus from patients with pneumonia in China, 2019. N Engl J Med 2020; 382: 727-33. (doi: 10.1056/NEJMoa2001017).

20. WHO: Coronavirus. 2020. Available at: https://www. who.int/health-topics/coronavirus\#tab=tab_1

21. Adhikari SP, Meng S, Wu Y-J, Mao Y-P, Ye R-X, Wang Q-Z, et al. Epidemiology, causes, clinical manifestation and diagnosis, prevention and control of coronavirus disease (COVID-19) during the early outbreak period: a scoping review. 2020. (doi: 10.1186/s40249-020-00646-x).

22. Fehr AR, Channappanavar R, Perlman S. Middle East respiratory syndrome: emergence of a pathogenic human coronavirus. Annu Rev Med. 2017; 68: 387-99. (doi: 10.1146/annurev-med-051215-031152).
23. WHO. Situation Reports. Coronavirus Disease (COVID-19) situation report. 2020. https://www.who.int/emergen cies/diseases/novel-coronavirus-2019/situation-reports (Accessed: May 20, 2020).

24. Worldometer: COVID-19 Coronavirus pandemic. 2020. Available at: https://www.worldometers.info/ coronavirus/ (Accessed: May 20, 2020).

25. Aljazeera. News /Health. Which countries have not reported coronavirus cases? 2020. Available at: https://www.aljazeera.com/news/2020/04/countriesreported-coronavirus-cases-200412093314762.html (Accessed: May 3, 2020).

26. Calvo RA, Deterding $S, \&$ Ryan RM. Health surveillance during COVID-19 pandemic. BMJ 2020; 369: m1373. (doi: 10.1136bmj.m1373).

27. Domestic Preparedness: The Use of mHealth Technology for Pandemic Preparedness. 2012. Available at: https://www.domprep.com/healthcare/the-use-ofmhealth-technology-for-pandemic-preparedness/ (Accessed: May 20, 2020).

28. Junhua L, Moore N, Akter S, Bleisten S \& Ray P. mHealth for Influenza Pandemic Surveillance in Developing Countries. HICSS 2010: 1530-605. (doi: 10.1109/HICSS.2010.274).

29. Who've you been with? Mobile technology helps to fight Covid. 2020. Available at: https://www.capacitymedia. com/articles/3825204/whove-you-been-with-mobiletechnology-helps-to-fight-covid-19-virus (Accessed: May 20, 2020).

30. Time: The Tech That Could Be Our Best Hope for Fighting COVID-19. 2020. Available at: Available at: https://time.com/5805622/coronavirus-pandemictechnology/ (Accessed: May 20, 2020).

31. PYMNTS: China Uses Alipay to Deply Color-Coded Health Rating App. 2020. Available at: https://www.google. com/amp/s/www.pymnts.com/news/international/202 0/coronavirus-prompts-china-to-deploy-color-codedhealth-rating-app/amp/ (Accessed: May 20, 2020).

32. New York Times: In Coronavirus Fight, China Gives a Color Code With Red Flags. 2020. Available at: https://www.google.com/amp/s/www.nytimes.com/20 20/03/01/business/china-coronavirussurveillance.amp.html (Accessed: May 20, 2020). 
33. Times of Israel: Health Ministry launches phone app to help prevent spread of coronavirus. 2020. Available at: https://www.timesofisrael.com/health-ministrylaunches-phone-app-to-help-prevent-spread-ofcoronavirus/ (Accessed: May 20, 2020).

34. How modern technology is helping in the fight against COVID-19. 2020. Available at: https://www.benjamin dada.com/how-tech-fight-covid-19/ (Accessed: May 20, 2020)

35. Africa Roundup: Africa's Tech Ecosystem Responds to COVID-19. 2020. https://techcrunch.com/2020/03/31/ Africa-roundup-africas-tech-ecosystem-responds-tocovid-19/ (Accessed: May 20, 2020).

36. World Economic Forum: Here's how Africans are using tech to combat the coronavirus pandemic. 2020. Available at https://www.weforum.org/agenda/2020/ 04/africa-technology-coronavirus-covid19-innovationmobile-tech-pandemic/ (Accessed: May 20, 2020).
37. World Health Organization: Classification of digital health interventions v1.0. Available at: http://www.who.int/reproductivehealth/publications/m health/classification-digital-health-interventions/en/ (Accessed: May 20, 2020).

38. Oza S, Jazayeri D, Teich JM, Ball E, Nankubuge PA, Rwebembera J et al. Development and deployment of the OpenMRS-Ebola Electronic Health Record system for an Ebola treatment center in Sierra Leone. J Med Internet Res 2017; 19(8): e294. (doi: 10.2196/jmir.7881).

39. Greenberg A, Haney D, Blake K, Moser R \& Hesse B. Differences in access to and use of electronic personal health information between rural and urban residents in the United States. J Rural Health. 2018; 34 Suppl 1(Suppl 1): s30-s38. (doi: 10.111/jrh.12228).

40. Marc M, Lena K. Digital Technology and the Future of Health Systems. Health Systems \& Reform. 2019; (5)2: 113-120. (doi: 10.1080/23288604.2019.1583040). 